\title{
PAINFUL BLADDER SYNDROME/INTERSTITIAL CYSTITIS (PBS/IC)- MEDICAL MANAGEMENT OPTIONS
}

\author{
Guda Manohar1, Duppala Radha Krishnan²
}

${ }_{1}^{1}$ Assistant Professor, Department of Urology, Andhra Medical College, Visakhapatnam, Andhra Pradesh.

${ }^{2}$ Consultant Urologist, Surya Hospital, Visakhapatnam, Andhra Pradesh.

\begin{abstract}
BACKGROUND
PBS/IC is a chronic pain syndrome of unknown aetiology. It represents a spectrum of disorders rather than one single disease. It is a diagnosis of exclusion. Evidence based treatment strategy is impossible, but conservative oral treatment may be effective in some patients.

Limitations- Patients with unremitting frequency, urgency, nocturia, suprapubic pain relieved with voiding were evaluated. Out of 450 patients investigated, 60 patients were selected for the study. Only patients who had fulfilled the NIDDK exclusion and inclusion criteria were included in this present study. Since the study duration was short, we had to limit the sample size for convenience.

Objective/Aim- To study the medical management options of painful bladder syndrome/ interstitial cystitis (PBS/IC)monotherapy versus multimodality therapy.
\end{abstract}

ABSTRACT

\section{MATERIALS AND METHODS}

Questionnaire based study was conducted on 450 patients between August 2008 and August 2017. 60 patients were selected for the present study based on National Institute of Diabetes and Digestive and Kidney Diseases (NIDDK) inclusion and exclusion criteria for diagnosis of PBS/IC. 54 patients were women and 6 patients were men with a mean age of 44 yrs. and $20 \%$ were over 60 yrs. of age. Overall, $48 \%$ received pentosan alone and 52\% received pentosan plus gabapentin and hydroxyzine. During interview, three questionnaires were administered. One related to pain/ discomfort scores, second overall investigator evaluation after treatment, third efficacy of pentosan alone and in combination with other drugs. Improvement of $>50 \%$ was considered as success.

\section{RESULTS}

Combined treatment with hydroxyzine, pentosan and gabapentin showed better clinical response 12 patients (40\%) compared to monotherapy with pentosan 9 patients $(30 \%)$.

\section{CONCLUSION}

Simultaneous multiple drug initiation can yield better results compared to single drug as PBS/IC is a clinical syndrome of multifactorial aetiology.

\section{KEYWORDS}

Painful Bladder Syndrome; Interstitial Cystitis; Pentosan; Hydroxyzine; Gabapentin.

HOW TO CITE THIS ARTICLE: Manohar G, Krishnan DR. Painful Bladder Syndrome/ Interstitial Cystitis (PBS/ IC)- Medical Management Options. J. Evolution Med. Dent. Sci. 2018;7(11):1353-1355, DOI: 10.14260/jemds/2018/307

\section{BACKGROUND}

Painful bladder syndrome/ interstitial cystitis (PBS/IC) is a clinical diagnosis. It is a chronic illness based on exclusion of other diseases with similar symptoms. ${ }^{1}$

Characterised by urinary frequency, nocturia, urgency and pelvic/ bladder pain of more than 6 weeks' duration, in the absence of proven urinary infection or other obvious pathology.2 Interstitial cystitis has no clear aetiology or pathophysiology and diagnostic criteria for the syndrome remain undefined. ${ }^{3}$ Possible causative factors are defect in glycosaminoglycan (GAG) layer, dysregulated immune or inflammatory signals, neural hypersensitivity and pelvic floor

'Financial or Other Competing Interest': None.

Submission 09-11-2017, Peer Review 27-02-2018,

Acceptance 07-03-2018, Published 12-03-2018.

Corresponding Author:

Duppala Radha Krishnan,

Consultant Urologist, Surya Hospital,

Visakhapatnam, Andhra Pradesh.

E-mail: radhasatwikuro@yahoo.co.in

DOI: $10.14260 /$ jemds $/ 2018 / 307$ dysfunction. A commonly accepted theory is that symptoms of PBS/IC may arise due to a defect in the glycosaminoglycan (GAG) layer covering the bladder urothelium. ${ }^{4}$ GAG layer acts as a barrier between toxins and bladder urothelium, and protects it from injury by these toxins. Deficiency in the surface GAG-mucin layer allows toxins to permeate bladder wall, which leads to inflammation and pain. Clinically, interstitial cystitis is often divided into 2 distinct subgroups based on findings at cystoscopy, bladder over distention and histologic features-ulcerative (classic) and non-ulcerative types. ${ }^{5}$ Such differences may have important implications for diagnosis and therapy. In the absence of universally effective treatment, therapy usually consists of various supportive, behavioural and pharmacologic measures. Surgical intervention is rarely indicated.

Currently, there are no specific clinical, urinary marker, radiographic, laboratory or serologic findings available. Biopsy findings are not pathognomonic for interstitial cystitis. The syndrome remains a diagnosis of exclusion. The most promising urinary biomarker for IC/ BPS is antiproliferative factor (APF). ${ }^{6}$ 


\section{Objective}

1. To compare the efficacy of single drug (Pentosan polysulphate) versus multiple drug therapy in interstitial cystitis/ painful bladder syndrome.

2. It is a non-randomised controlled study (NRCT) spread over 10 years. As IC/ PBS is a chronic condition and treatment will not result in total cure, but only alleviate the disease condition this protocol is used for IC/ PBS there is no cure.

\section{MATERIALS AND METHODS \\ Objective}

1. To compare the efficacy of single drug (Pentosan polysulphate) versus multiple drug therapy in interstitial cystitis/ painful bladder syndrome.

2. It is a non-randomised controlled study (NRCT) spread over 10 years, as IC/ PBS is a chronic condition and treatment will not result in total cure, but only alleviate the disease condition. This protocol is used for IC/PBS, there is no cure.

3. Sample size was not predetermined. After NIDDK exclusion criteria, patients were selected. Since the study duration was short, we had to limit the sample size for convenience.

4. A systematic review of the available literature was conducted to identify the various oral treatment modalities available for painful bladder syndrome/interstitial cystitis (PBS/IC).

\section{Statistical Methods}

Descriptive statistics. Qualitative variables were analysed using proportions. Quantitative variables were analysed using mean and standard deviation. Chi-square test was applied to note if there is any statistical significance between the single drug regimen and the multidrug therapy. A ' $\mathrm{p}$ ' value less than 0.05 was considered statistically significant.

It is a non-randomised, controlled study where comparison was made between two medications. Questionnaire based study was conducted on 60 patients between August 2008 to August 2017. 54 patients were women and 6 patients were men with a mean age of 44 yrs. (range $24-60$ ) and 20\% were over 60 yrs. of age. All patients met the NIDDK definition for PBS/ IC based on the results of laboratory cystoscopy, cytology and biopsy. Screened patients were enrolled for 6 months treatment schedule. Patients who have stopped medication due to poor outcome or side effects are not included in the study. 29 patients were given pentosan sulphate $100 \mathrm{mg}$ three times a day. Gabapentin (methylcobalamin 1500 mcg OD) and hydroxyzine (25 mg OD) were added to pentosan sulphate for 31 patients. Patient's own assessment of bladder pain was the basis of clinical improvement. Improvement of more than $50 \%$ was considered as success.

\section{Every Three Months the Patients Rating}

Of overall change in pain in comparison to baseline and difference in pain/ discomfort scores were evaluated. At baseline pain/ discomfort scores were severe in 36 patients $(60 \%)$, moderate in 21 patients (35\%) and mild in 3 patients (5\%). At three months, $30 \%$ (9 patients) in the study had pain scores that improved by pentosan alone compared to
$40 \%$ (12 patients) with combination therapy. It was found patients responded better with multimodality therapy.

\section{RESULTS}

Combined treatment with hydroxyzine, pentosan and gabapentin (methylcobalamin) showed better clinical response $(40 \%)$ compared to monotherapy with pentosan (30\%).

\begin{tabular}{|c|c|c|}
\hline $\begin{array}{c}\text { Efficacy } \\
\text { Parameter }\end{array}$ & Pentosan & $\begin{array}{c}\text { Combination } \\
\text { Therapy }\end{array}$ \\
\hline $\begin{array}{c}\text { Patient's overall } \\
\text { change in pain } \\
\text { (recollection of } \\
\text { difference between } \\
\text { current pain and } \\
\text { baseline pain) }\end{array}$ & $\begin{array}{c}\mathrm{N}=29 \\
\text { Median=3 }\end{array}$ & $\begin{array}{c}\mathrm{N}=31 \\
\text { CI: }(3.37,3.51) \\
\text { Mean }=3.91\end{array}$ \\
\hline $\begin{array}{c}\text { Patient's } \\
\text { CI: }(3.83,3.99)\end{array}$ \\
satisfaction & 09 patients/ (30\%) & 12 patients (40\%) \\
\hline \multicolumn{2}{|c|}{ Table 1. Pain Scores in Reference to Baseline } \\
\hline
\end{tabular}

$\mathrm{N}=$ No. of patients six-point scale, $1=$ worse; $2=$ no better; $3=$ slightly improved; $4=$ moderately improved; $5=$ greatly improved; $6=$ symptom gone, $\mathrm{CI}$ : $95 \%$ confidence interval.

\begin{tabular}{|c|c|c|c|}
\hline Parameter & $\begin{array}{c}\text { Combination } \\
\text { Therapy }\end{array}$ & Pentosan & P-value \\
\hline $\begin{array}{c}\text { Overall investigator } \\
\text { evaluation }\end{array}$ & $\begin{array}{c}12 \text { patients } \\
(41 \%)\end{array}$ & $\begin{array}{c}9 \text { patients } \\
(26 \%)\end{array}$ & 0.03 \\
\hline Patient assessment & $\begin{array}{c}12 \text { patients } \\
(40 \%)\end{array}$ & $\begin{array}{c}8 \text { patients } \\
(25 \%)\end{array}$ & 0.04 \\
\hline Overall improved & $\begin{array}{c}12 \text { patients } \\
(40 \%)\end{array}$ & $\begin{array}{c}9 \text { patients } \\
(27 \%)\end{array}$ & 0.08 \\
\hline Pain questionnaire & $\begin{array}{c}\text { Table 2. Response Assessment after 3 and 6 Months of } \\
\text { Treatment (Percentage of Patients Improved) Investigator } \\
\text { Evaluation }\end{array}$ \\
\hline
\end{tabular}

Efficacy outcomes were based on a follow-up questionnaire completed by the patient after three and six months. Patients were asked if they felt improved overall compared to the beginning of the study, and if they had improved they were asked to rate the improvement as slight $(25 \%)$, moderate $(50 \%)$, great $(75 \%)$ or complete cure $(100 \%)$. Investigators could rate patients as worse, no change, fair, good, very good or excellent.

\begin{tabular}{|c|c|c|c|}
\hline $\begin{array}{c}\text { Patient-Rated } \\
\text { Improvement }\end{array}$ & $\begin{array}{c}\text { Combination } \\
\text { Therapy }\end{array}$ & Pentosan & $\begin{array}{c}\text { P- } \\
\text { value }\end{array}$ \\
\hline Overall & 13 patients (42\%) & $\begin{array}{c}8 \text { patients } \\
(26 \%)\end{array}$ & 0.01 \\
\hline Pain Questionnaire & 15 patients (48\%) & $\begin{array}{c}8 \text { patients } \\
(28 \%)\end{array}$ & 0.01 \\
\hline Pain Scale & 23 patients (76\%) & $\begin{array}{c}18 \text { patients } \\
(61 \%)\end{array}$ & 0.005 \\
\hline Pressure to Urinate & 12 patients (40\%) & $\begin{array}{c}8 \text { patients } \\
(28 \%)\end{array}$ & 0.04 \\
\hline Urgency Scale & 22 patients (71\%) & $\begin{array}{c}15 \text { patients } \\
(53 \%)\end{array}$ & 0.01 \\
\hline $\begin{array}{c}\text { Improved Sexual } \\
\text { Intercourse }\end{array}$ & 13 patients (41\%) & $\begin{array}{c}8 \text { patients } \\
(28 \%)\end{array}$ & 0.06 \\
\hline
\end{tabular}

Table 3. Response (Patient-Rated) post 3 and 6 Months

Treatment with Pentosan/Combination Therapy (\% Improvement) 


\section{DISCUSSION}

Education, emotional support, behavioural modifications and stress management remains the mainstay of treatment. No long-term therapy has been shown to prevent or delay recurrent episodes. Periodic exacerbations are managed to palliate and alleviate symptoms, because no discrete pathognomonic pathologic criteria exist for assessing and monitoring disease severity. Indications and goals for treatment are based on the degree of patient's symptoms. Assessing patient response to treatment is also complicated because of the subjective nature of symptoms; the waxing and waning nature of symptoms without treatment; and the lack of objective serologic, physical or histopathologic findings. Conservative measures, oral or intravesical treatments are considered first-line treatment. Patients may require trials of multiple therapeutic options including combination therapy. Apart from pain management, pentosan polysulphate, gabapentin, amitriptyline, cimetidine, hydroxyzine and cyclosporine are used. ${ }^{7}$ Pentosan is the only oral drug currently approved by US FDA for the treatment of PBS/ IC. ${ }^{8}$ It promotes restoration of the defective GAG (mucin) layer, thereby preventing further urothelial insult. ${ }^{9}$ Bladder epithelial permeability is reduced with pentosan treatment with reduction in bladder mucosal inflammation. ${ }^{10}$ Pentosan also decreases histamine secretion by inhibiting the stimulation of connective tissue and mucosal mast cells. ${ }^{11}$ The duration of therapy with pentosan appears to be more important in symptom alleviation than the dosage. Dose is $100 \mathrm{mg}$ capsules orally three times daily. The capsules should be taken with water at least 1 hour before or 2 hours after the meals. ${ }^{12}$ Side effects are alopecia, diarrhoea, nausea, rash, liver function abnormalities, pruritus and rectal haemorrhage. ${ }^{13}$ Reassessment after 3 months is required for patients receiving pentosan in case no improvement is observed and limiting adverse event are not present. Pentosan may be continued for another 3 months or combination therapy is initiated in patients whose pain is not improved by 6 months of treatment. The clinical value and risks of continued treatment are unknown.

Hydroxyzine (anti-histamine) blocks neuronal activation of mast cells, thus suppressing mast cell degranulation. ${ }^{14}$ Dosing starts at $25 \mathrm{mgs}$ given at bed time and may increase to $50 \mathrm{mgs}$ at night and $25 \mathrm{mgs}$ in the morning. Gabapentin (Methylcobalamin is useful for neuropathic pain). Side effects are dizziness, dry mouth, nausea, drowsiness, blurred vision, dry mouth and headache. Opioids and NSAIDs are used for pain management.

\section{Limitations}

Since the study duration was short, we had to limit the sample size for convenience.

\section{CONCLUSION}

Simultaneous multiple drug initiation can yield better results compared to single drug as PBS/IC is a clinical syndrome of multifactorial aetiology compared to monotherapy with pentosan (30\%). Maximum treatment response can be achieved when patients are treated for 6 months or longer. Currently, pentosan polysulphate is the only approved drug for PBS/IC, because PBS/IC is a chronic condition. Long term treatment would be required. Optimising medication for tolerability is critical to obtaining patient's compliance. Choosing the formulation with the lowest likelihood of adverse events may improve compliance.

\section{REFERENCES}

[1] Arora HC, Shoskes DA. The enigma of men with interstitial cystitis/bladder pain syndrome. Translational Andrology and Urology 2015;4(6):66876.

[2] Marshall K. Interstitial cystitis: understanding the syndrome. Altern Med Rev 2003;8(4):426-37.

[3] Habermacher GM, Chason JT, Schaeffer AJ. Prostatitis/chronic pelvic pain syndrome. Annu Rev Med 2006;57:195-206.

[4] Nickel JC. Diagnosis of interstitial cystitis: another look. Rev Urol 2000;2(3):167.

[5] Sant GR. Etiology, pathogenesis and diagnosis of interstitial cystitis. Rev Urol 2002;4(Suppl 1)S9-S15.

[6] Keay SK, Zhang CO, Shoenfelt J, et al. Sensitivity and specificity of antiproliferative factor, heparin-binding epidermal growth factor-like growth factor, and epidermal growth factor as urine markers for interstitial cystitis. Urology 2001;57(6 Suppl 1)9-14.

[7] Evans RJ. Treatment approaches for interstitial cystitis: multimodality therapy. Rev Urol 2002;4(Suppl 1)S16-S20.

[8] Hanno PM, Burks DA, Clemens JQ, et al. AUA guideline for the diagnosis and treatment of interstitial cystitis/bladder pain syndrome. J Urol 2011;185(6):2162-70.

[9] Teichman JM. The role of pentosan polysulfate in the treatment approaches for interstitial cystitis. Rev Urol 2002;4(Suppl 1):S21-S7.

[10] Anderson VR, Perry CM. Pentosan polysulfate: a review of its use in the relief of bladder pain or discomfort in interstitial cystitis. Drugs 2006;66(6):821-35.

[11] Lau TC, Bengston JM. Management strategies for painful bladder syndrome. Reviews in Obstetrics and Gynecology 2010;3(2):42-8.

[12] Sant GR, Propert KJ, Hanno PM, et al. A pilot clinical trial of oral pentosan polysulfate and oral hydroxyzine in patients with interstitial cystitis. J Urol 2003;170(3):810-5.

[13] Elmiron. In: Physicians' desk reference. 60th edn. Montvale, NJ: Thomson PDR 2006: p. 2393-5.

[14] Atarax. In: The Physicians' desk reference. 53 ${ }^{\text {rd }}$ edn. Montvale, NJ: Physicians' Desk Reference Inc, 1999: p. 2367-8. 